Open Access

\title{
Barriers to recognition of out-of-hospital cardiac arrest during emergency medical calls: a qualitative inductive thematic analysis
}

David Alfsen ${ }^{1 *}$, Thea Palsgaard Møller ${ }^{1,2}$, Ingrid Egerod ${ }^{2,3}$ and Freddy K. Lippert ${ }^{1,2}$

\begin{abstract}
Background: The chance of surviving out-of-hospital cardiac arrest (OHCA) depends on early and correct recognition of cardiac arrest by the emergency medical dispatcher during the emergency call. When cardiac arrest is identified, telephone guided cardiopulmonary resuscitation (CPR) and referral to an automated external defibrillator should be initiated. Previous studies have investigated barriers to recognition of OHCA, and found the caller's description of sign of life, the type of caller, caller's emotional state, an inadequate dialogue during the emergency call, and patient's agonal breathing as influential factors. Though many of these factors are included in the algorithms used by medical dispatchers, many OHCA still remain not recognised. Qualitative studies investigating the communication between the caller and dispatcher are very scarce. There is a lack of knowledge about what influences the dispatchers' recognition of OHCA, focusing on the communication during the emergency call.

The purpose of this study is to identify factors affecting medical dispatchers' recognition of OHCA during emergency calls in a qualitative analysis of calls.

Methods: An investigator triangulated inductive thematic analysis of recordings of out-of-hospital cardiac arrest emergency calls from December 2012. Participants were the callers (bystanders) and the emergency medical dispatchers. Data were analysed using a hermeneutic approach.

Results: Based on the concept of data saturation, 13 recordings of not recognised cardiac arrest and 8 recordings of recognised cardiac arrests were analysed. Three main themes, six subthemes and an embedded theme emerged from the analysis: caller's physical distance (caller near patient, caller not near patient), caller's emotional distance (keeping calm, losing control), caller is a healthcare professional (responsibility is handed over to the caller, caller assumes responsibility), and the embedded theme: caller assesses the patient.
\end{abstract}

Conclusion: The physical and emotional proximity of the caller (bystander) as well as the caller's professional background affect the dispatcher's chances of correct recognition and handling of cardiac arrest. The dispatcher should acknowledge the triple roles of conducting patient assessment, instructing the caller, and reassuring the emotionally affected caller.

\footnotetext{
* Correspondence: david.alfsen@gmail.com

${ }^{1}$ Emergency Medical Services Copenhagen, The Capital Region of Denmark,

Telegrafvej 5, 2750 Ballerup, Denmark

Full list of author information is available at the end of the article
}

\section{Biomed Central}

(c) 2015 Alfsen et al. Open Access This article is distributed under the terms of the Creative Commons Attribution 4.0 International License (http://creativecommons.org/licenses/by/4.0/), which permits unrestricted use, distribution, and reproduction in any medium, provided you give appropriate credit to the original author(s) and the source, provide a link to the Creative Commons license, and indicate if changes were made. The Creative Commons Public Domain Dedication waiver (http://creativecommons.org/publicdomain/zero/1.0/) applies to the data made available in this article, unless otherwise stated. 


\section{Background}

The chance of surviving from out-of-hospital cardiac arrest (OHCA) is highly associated with emergency medical dispatchers' recognition of the condition during emergency calls, early bystander cardiopulmonary resuscitation (CPR), and early defibrillation [1-4]. It is essential that the emergency medical dispatcher (EMD) recognises OHCA, so telephone assisted CPR $(\mathrm{tCPR})$ and referral to an automated external defibrillator (AED) can be initiated. Earlier studies have investigated barriers to recognition of OHCA, and found the caller's description of signs of life, the type of caller, caller's emotional state, inadequate dialogue during the emergency call, and patient's agonal breathing as influential factors. Moreover, successful recognition of OHCA is associated with an assessment of the patient's consciousness, breathing pattern, and facial colour [5-9]. Many of these factors are included in the algorithms used by medical dispatchers, but still, not all OHCA's are recognised [10-19]. A better understanding of factors leading to successful recognition of OHCA has the potential to increase the proportion of bystander CPR, and thereby improve survival rate [20]. Qualitative studies investigating recognition of OHCA, focusing on the communication between caller and dispatcher are needed. The aim of this study was to identify factors affecting medical dispatchers' recognition of OHCA during emergency calls in the Emergency Medical Services (EMS), Copenhagen using a qualitative analysis.

\section{Methods}

\section{Setting}

The study took place at the Emergency Medical Dispatch Center (EMDC) in Copenhagen, Denmark serving a population of 1.7 million and responding to about 110.000 emergency calls annually. In Denmark, there is a single emergency phone number (1-1-2) leading to an emergency call center. In case of a medical problem, the caller is re-directed to an EMDC that responds to the call by activating the appropriate response. The medical dispatchers are specially trained registered nurses and paramedics who are supported by a criteria-based, nationwide priority tool (Danish Index for Emergency Care) [21]. For each call, the system recommends a response according to contact cause and urgency of the condition. The algorithm is described in Fig. 1, and the response types are described in Table 1.

In each emergency call, the dispatcher starts by asking the caller "How can I help you?" and then assesses the patient's consciousness and breathing pattern. If an OHCA is suspected, the dispatcher provides telephone assisted CPR to the bystander and refers to the nearest AED. In case of suspected OHCA, a high priority response including an emergency physician is dispatched.

\section{Study design}

An inductive qualitative approach was chosen, using recordings of emergency calls including recognised and not recognised OHCA as the source of data. The participants were callers (bystanders) and medical dispatchers. The goal of qualitative research is to understand and describe a phenomenon, including its definition, terminology and relation to other phenomena [22, 23]. Detailed description of the caller-dispatcher conversation during emergency calls paves the way to a better understanding of why OHCA is or is not recognised during the emergency call. The study was conducted in two steps: 1) sorting the recordings according to recognised and not recognised $\mathrm{OHCA}$, and 2) analysing the recordings and identifying factors related to recognised and unrecognised OHCA.

\section{Preconceptions of the investigators}

An active and deliberate relationship to their preconception or potential prejudices can aid the investigators to learn from the data [22]. In the present study, the team of investigators analysing data consisted of a registered nurse (DA), a physician (TPM), a professor in clinical nursing (IE), and the medical director of EMS Copenhagen (FKL). The specific knowledge of OHCA and EMS systems were paramount to the sorting of data items, while the difference in experience and interdisciplinary knowledge among team members facilitated critical reflection and reduced blind spots. The use of investigator triangulation strengthens the design by supplementing and challenging the investigators' statements during the process of analysis [22, 24].

\section{Sampling strategy}

The sample was collected in December 2012 (31 days) and the sampling strategy was criterion-based selection [22]. The calls during December 2012 were chosen because they were the most recent calls available. The criterion for selection were all calls regarding sudden unexpected cardiac arrest. Cardiac arrest due to trauma, terminal disease and patients with definite signs of death (head separated from body, rigor mortis, incineration etc.) were excluded. The OHCA calls were identified by merging databases containing mobile critical care unit charts and EMDC data. OHCA was considered as recognised if CPR was encouraged, guided, or conducted at any time during the call. Sample size was determined by saturation of data, which means that inclusion of calls continued until information became redundant, and the themes appeared robust [22].

\section{Analysis}

Thematic analysis as described by Braun \& Clarke was used, which identifies, analyses, and describes patterns in data [24]. The method is not bound by any specific theory, 


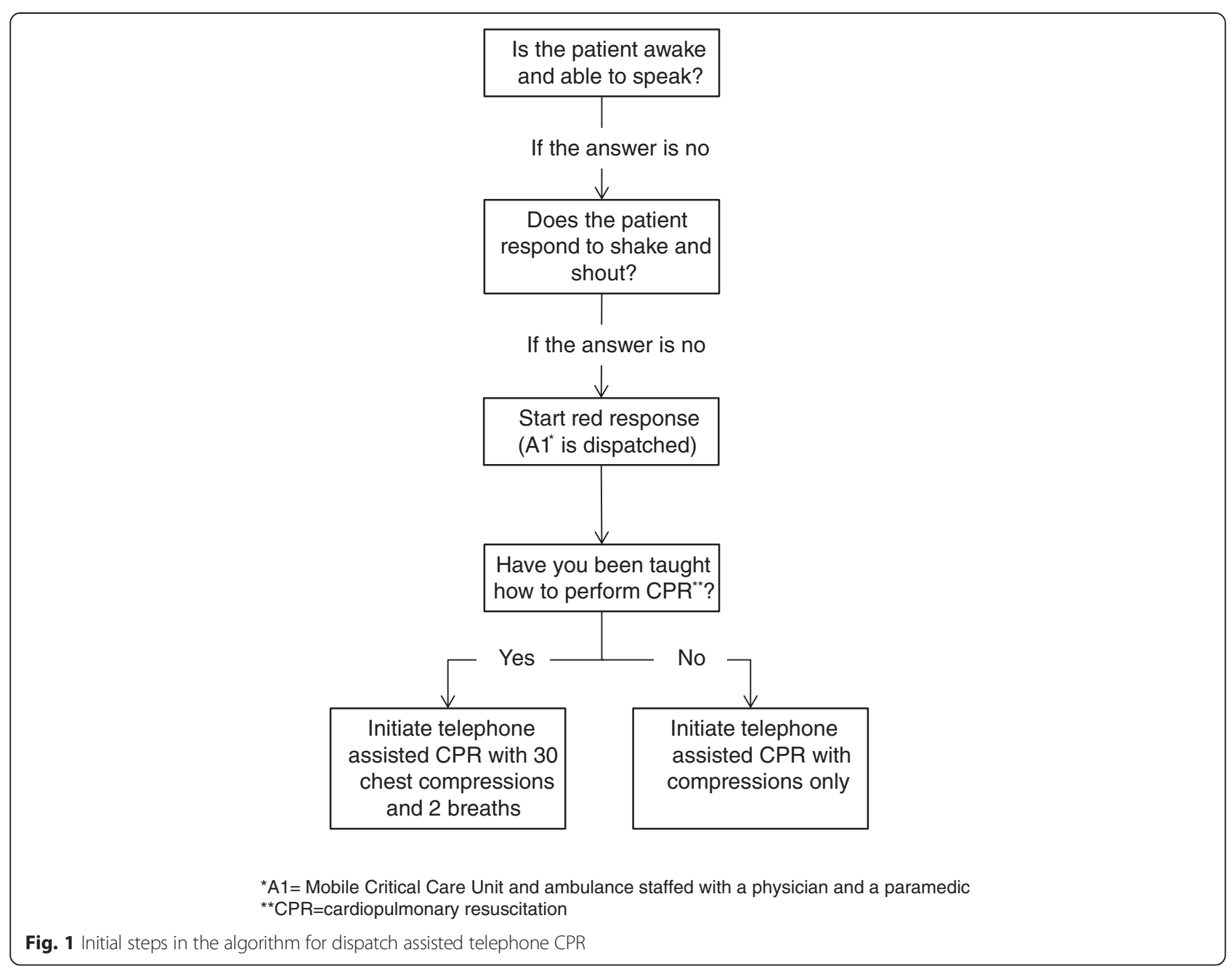

and does not put any specific demands on the data collection method. This pragmatic methodology lends itself for this study, because of the exploratory focus. The process of thematic analysis progresses through six phases: Phase 1: Familiarisation with data, phase 2: generating initial codes, phase 3: searching for themes, phase 4: reviewing themes, phase 5 defining and naming themes, and phase 6: producing the report. Analysis continued until saturation, viz. when information became redundant. Recordings were transcribed by simple orthographic method [24]. During analysis the recordings were played as a

Table 1 Emergency response types

\begin{tabular}{lc}
\hline Emergency (lights and siren) & Urgent (no lights and siren) \\
\hline $\begin{array}{l}\text { A1: Mobile Critical Care Unit with } \\
\text { physician and an ambulance } \\
\text { staffed with paramedics }\end{array}$ & $\begin{array}{c}\text { B1: Any ambulance (lights } \\
\text { and siren if necessary) }\end{array}$ \\
\begin{tabular}{ll} 
A2: Ambulance with paramedics & B2: Ambulance with paramedics \\
A3: Ambulance with emergency & B3: Ambulance with emergency \\
medical technicians & medical technicians \\
\hline
\end{tabular}
\end{tabular}

supplement to transcribed data in order to exploit contextual nuances [22, 24].

\section{Ethical considerations}

The study was approved by the local ethics committee, ref. no. H-2-2014-FSP19, the Danish data protection agency, ref. no. HEH-2013-012, and I-suite no. 02112.

\section{Results}

We included 21 emergency calls in the study; 8 with recognised OHCA and 13 with not recognised OHCA. Tables 2 and 3 show an identification number for each call, patient age and gender, the caller's relation to the patient, the caller's proximity to the patient and the assigned response to the emergency call for recognized and not recognised OHCA, respectively.

\section{Themes}

Three themes emerged during analysis (Table 4): caller's physical distance (caller near patient, caller not near 
Table 2 Characteristics for emergency calls concerning recognised OHCA

\begin{tabular}{|c|c|c|c|c|c|c|}
\hline Patient no. & Patient age & Patient gender & Caller's relation to patient & Caller's proximity to patient & Response & Emergency physician treatment \\
\hline 1 & 40 & Female & Spouse & With patient & $\mathrm{A} 1$ & Resuscitation success \\
\hline 2 & 47 & Male & Friend & With patient & $\mathrm{A} 1$ & Resuscitation success \\
\hline 3 & 64 & Female & Son in law & With patient & A1 & No treatment \\
\hline 4 & 74 & Male & Nursing home staffa & With patient & $\mathrm{A} 1$ & Resuscitation success \\
\hline 5 & 75 & Male & Spouse & Near patient & $\mathrm{A} 1$ & Resuscitation success \\
\hline 6 & 81 & Male & Spouse & With patient & A1 & Resuscitation failed \\
\hline 7 & 83 & Female & Nurse $^{a}$ & With patient & A1 & No treatment \\
\hline 8 & 84 & Male & Nursing home staffa & With patient & A1 & No treatment \\
\hline
\end{tabular}

Patients: 5 male, 3 female, median age 74 years (40-84); caller: 3 healthcare professionals ${ }^{a}$, and 5 non-healthcare professionals. With patient: The caller can see the patient. Near patient: The caller cannot see the patient, but communicate with person with a person together with the patient . Resuscitation success: CPR successful. Resuscitation failed: CPR attempted, but unsuccessful. No treatment: CPR not attempted. A1 = Mobile Critical Care Unit and ambulance staffed with paramedic

patient), caller's emotional distance (keeping calm, losing control), caller is a healthcare professional (responsibility is handed over to the caller, caller assumes responsibility), and one embedded theme: Caller assesses the patient.

\section{Caller's physical distance Caller near patient}

In all recognised OHCA calls, the caller was in close proximity to the patient. This enabled better communication and assessment, and the medical dispatcher was able to react quickly to information and initiate the EMD algorithm systematically with little or no interruption. If the caller was with a patient and able to describe abnormal breathing, OHCA was recognised at an early stage. During some calls the callers presented a patient with normal breathing, which changed the structure of the conversation. The dispatchers then abandoned the algorithm in favour of providing first aid, and thereby missed the provision of tCPR. If the caller stated later that the patient was deteriorating, the algorithm was applied again. This was evident in several calls where the caller interrupted the dispatcher, to describe the new situation. In the following quotation, the caller initially set the scene by presenting a respiratory problem. The dispatcher was able to explore the situation and apply the algorithm.

[Patient 4] Dispatcher: "Hello this is the nurse from the dispatch centre". Caller: "I'm calling from [nursing home]. I have a resident who has fallen and now he has trouble breathing; he is turning blue". Dispatcher: "He is turning blue?" Caller: "Yes". Dispatcher: "He is awake, isn't he?" Caller: "More or less; no he is not". Dispatcher: "He is not responsive?" Caller: "No, [calling name of patient]". Dispatcher: "Is he

Table 3 Characteristics for emergency calls concerning not recognised OHCA

\begin{tabular}{|c|c|c|c|c|c|c|}
\hline Patient no. & Patient age & Patient gender & Caller's relation to patient & Caller's distance to patient & Response & Emergency physician treatment \\
\hline 9 & 32 & Male & Mother & With patient & A3 & Resuscitation success \\
\hline 10 & 49 & Female & Spouse & With patient & $\mathrm{A} 2$ & Resuscitation failed \\
\hline 11 & 59 & Female & Neighbour & With patient & $\mathrm{A} 2$ & Resuscitation failed \\
\hline 12 & 68 & Male & Nursing home nurse ${ }^{a}$ & With patient & $\mathrm{A} 1$ & Resuscitation failed \\
\hline 13 & 71 & Male & Daughter in law & Not at scene & A3 & Resuscitation failed \\
\hline 14 & 74 & Male & Spouse & With patient & $\mathrm{A} 1$ & Resuscitation failed \\
\hline 15 & 77 & Female & General Practitioner $^{a}$ & Not at scene & A3 & No treatment \\
\hline 16 & 80 & Female & Spouse & With patient & $\mathrm{A} 1$ & Resuscitation failed \\
\hline 17 & 80 & Male & Son in law & With patient & $\mathrm{A} 1$ & Resuscitation failed \\
\hline 18 & 83 & Female & Daughter & With patient & A3 & No treatment \\
\hline 19 & 88 & Female & Nursing home staffa & Near patient & $\mathrm{A} 2$ & No treatment \\
\hline 20 & 94 & Male & Spouse & Near patient & B2 & No treatment \\
\hline 21 & 98 & Male & Nursing home staffa & With patient & A1 & Resuscitation failed \\
\hline
\end{tabular}

Patients: 6 male, 7 female, median age 74 years (32-98); Caller: 4 healthcare professionals ${ }^{a}$ and 9 non-healthcare professionals. With patient: The caller can see the patient. Near patient: The caller cannot see the patient, but communicate with a person together with the patient. Not at scene: Caller in different location from the patient. Resuscitation success: CPR successful. Resuscitation failed: CPR attempted, but unsuccessful. No treatment: CPR not attempted. ${ }^{\mathrm{a}}$ Indicates healthcare professional. A1 = Mobile Critical Care Unit and ambulance staffed with paramedic, A2 = Ambulance staffed with a paramedic, A3 = Basic life support ambulance, B2 = Ambulance staffed with a paramedic, no lights and siren 
breathing?" Caller: "Well ... [pause]". Dispatcher: "I guess not. Then you should start CPR".

\section{Caller not near patient}

As soon as it was clear to the dispatcher that the caller was not present at the scene, the algorithm from the EMD was disregarded, and a response was dispatched based on the caller's description of the patient's condition. In cases where the caller was closer to the patient, but not in the same room, the dispatcher had to ask the caller to go to the patient and assess the patient. These situations seemed particularly challenging when the caller was emotionally affected by the situation. The dispatcher had a double role of calming the caller while gathering relevant information. In the following the caller is calling on behalf of his mother in another part of the country.

[Patient 13] Caller: "Yes, hello. You are speaking with [name]. My mother has just called, that her husband has collapsed. A couple of months ago he had an angioplasty". Dispatcher: "Yes". Caller: "and he has fainted and is unresponsive". Dispatcher: "I see". Caller: "She [mother] isn't well, has seizures and ..." Dispatcher: "Is it your mother or him?" Caller: "Him. My mother is so weak that she apparently isn't able to call [mother's location]. I am in [caller's location] and she lives at [mother's location]".

\section{Caller assesses the patient}

If the caller was close to the patient and able to make an assessment, this was reported to the dispatcher. In most of the recordings, the patient's problem was initially related to respiratory failure or loss of consciousness. The dispatcher explored these avenues using the algorithm, but if the caller stated that breathing was present, the algorithm for cardiac arrest was abandoned. In some cases, the dispatcher continued to obtain a patient history without recognizing the arrest until the arrival of ambulance. The following quote

Table 4 Themes and sub-themes regarding factors affecting dispatcher's recognition of OHCA during emergency calls

\begin{tabular}{lll}
\hline Themes & Sub-themes & $\begin{array}{l}\text { Embedded } \\
\text { theme }\end{array}$ \\
\hline Caller's physical distance & $\begin{array}{l}\text { Caller near the patient } \\
\text { Caller not near the patient }\end{array}$ & $\begin{array}{l}\text { Caller assesses } \\
\text { the patient }\end{array}$ \\
Caller's emotional distance & Keeping calm \\
& Losing control \\
Caller is a healthcare professional & Responsibility is handed \\
& $\begin{array}{l}\text { Over to the caller } \\
\text { Caller assumes } \\
\text { responsibility }\end{array}$ \\
\hline
\end{tabular}

illustrates a situation, where the caller believed the patient was breathing and the dispatcher as a consequence abandoned the algorithm.

[Patient 17] Dispatcher: "Okay, but is he unconscious and not reacting to pain?” Caller: "(...), well he is breathing (...), but not reacting”. Dispatcher: "Then you have to make sure he is breathing, and that he hasn't arrested (...) try to see if his chest is moving." Caller: "It is." Dispatcher: "It is, and is it moving properly?" Caller: "I would think so (...)".

\section{Caller's emotional distance Keeping calm}

In calls with recognised OHCA, the dispatcher was able to provide instructions to the caller in a calm, clear and direct way, and the caller followed the instructions. The caller became an active partner in patient assessment adding to the success of the call. The dispatcher was able to establish a good communication with the caller and systematically follow the algorithm. The following is an example of direct and good communication.

[Patient 2] Caller: "Come on, again. Breathe. It's as if he's dropping his tongue, like he can't hold it himself." Dispatcher: "No, but if you hold the jaw, pulling the" (caller interrupts) Caller: "I have two fingers inside the mouth, holding the tongue." Dispatcher: "You pull the jaw forward" (speaking slowly and loud). Caller: "Come on. Hell, yes there it was" (loud and strained, then relieved). Dispatcher: "That's great, and how is his colour now, any better?" Caller: "No, he is still completely blue and completely dead" (calm and clear). Dispatcher: "Try to put him onto his back. You have to start CPR."

\section{Losing control}

An emotionally affected caller had more trouble recognising OHCA. The dispatcher assessed the condition of the caller listening for signs of crying or talking. In not recognised OHCA the dispatcher might choose to calm the caller before continuing. In some cases, the dispatcher became emotionally affected in response to the caller's distress. In the following, the dispatcher tried to maintain patient assessment despite the distress of the caller.

[Patient 20] Dispatcher: "You need to pay attention; I'm going to ask you some questions. I already sent an ambulance, okay?" Caller: "Yes. (...)." Dispatcher: "Is he breathing, your husband? "Caller: "Yes, I hope (trembling voice)". Dispatcher: "What is the colour of his face?" (Interrupting) Caller: "Well I can't tell you more, now I have to go. You have to come (loud and 
determined)". (Interrupting) Dispatcher: "No, go and look at his face" (caller hangs up).

\section{Caller is a healthcare professional Responsibility is handed over to the caller}

When the dispatcher recognised the caller as a healthcare professional, the roles were reversed; the caller was given responsibility and took action while the dispatcher had a counselling role. In recordings with recognised OHCA, the caller recognized the warning signs. In the following the caller identified OHCA and the dispatcher initiated tCPR.

[Patient 8] Dispatcher: "Uhm, does he have any heart disease or pulmonary diseases?" Caller: "Yes, COPD and something with his heart". Dispatcher: "Okay, it can be either one or the other we are dealing with." Caller: "Yes, I just came here, because, uhm, I had to check his medications and will initiate a resuscitation attempt because he stopped breathing (...)." Dispatcher: "Do you have a defibrillator?" Caller: "No (...)." Dispatcher: "How's the breathing now?" Caller: "Right now he is pausing and the pauses are getting longer". Dispatcher: "How about the chest, does it move up and down when he breathes?" Caller: "Uhm, right now there is no breathing." Dispatcher: "Then you might want to start CPR".

\section{Caller assumes responsibility}

In some calls with not recognised OHCA, the dispatcher indirectly transferred the responsibility to the caller, if a healthcare professional. This phenomenon was characterised by a relaxed collegial atmosphere, where the algorithm for cardiac arrest was abandoned in favour of more informal assessment and the use of ambiguous terms, e.g. "fairly unconscious".

[Patient 21] Caller: "He is fairly unconscious at the moment (...)." Dispatcher: "Is he breathing now?" Caller: "He is breathing now and then, and then he stops, uhm, it sound like fluids are accumulating (...)". Dispatcher: "Okay, and now you are telling me that he is unconscious?" Caller: "He is unconscious now, yes." Dispatcher: "Yes, okay. And breathing is slower..." Caller: "Slower breathing (...)" Dispatcher: "Good, then that's settled, bye."

\section{Discussion}

The aim of this study was to identify factors affecting medical dispatchers' recognition of OHCA during emergency calls. The main findings included three themes: "caller's physical distance", "caller's emotional distance", and "caller is a healthcare professional". The dispatchers often had a triple role; trying to obtain patient information, instructing the caller, and calming the caller. This triple role was evident in two subthemes: "Caller not near the patient" and "losing control".

In our study, the dispatcher did not strictly use the cardiac arrest algorithm if the caller was not near the patient. This finding is supported by several studies that have demonstrated the distance between caller and patient being a potential barrier to the recognition of OHCA $[16,25-27]$. One study including interviews with 10 dispatchers showed that tCPR was unlikely if the caller was not at the scene [28]. The same study showed that the emotional state of the caller influenced initiation of tCPR. In accordance with our study, several studies have shown how the emotional state of the caller affected OHCA recognition and precluded tCPR [27, 29-31].

Our study has shown that it is risky if the dispatcher disregards the algorithm, even if the situation appears under control. Similar results have been reported in a recent study showing that the main barriers to recognition of OHCA were absence or incomplete assessment of breathing and the presence of agonal breathing [32].

In our sub-theme "losing control" we found that the emotional state of the caller could influence the dispatcher. We also observed the inherent emotional asymmetry between caller and dispatcher, as the caller was typically experiencing a unique and devastating situation, whereas the dispatcher was doing "business as usual". In the sub-theme "losing control" the asymmetry was evident, but in some cases the dispatchers also got close to losing control. If, on the other hand, the caller was calm, or reassured by the dispatcher, the asymmetry was replaced by a constructive and information rich conversation.

The characteristics of the callers, as illustrated in Tables 2 and 3, showed that all callers in the group that recognised $\mathrm{OHCA}$ were in close proximity to the patient. This was supported in the theme "caller's physical distance". Importantly, more patients were successfully resuscitated when OHCA was recognised, potentially increasing patients' chances of survival [20].

Surprisingly, the theme "caller is a healthcare professional", showed that the caller's profession did not necessarily increase the chances of OHCA recognition. Some of these callers were nursing home staff, and might not be as updated in emergency care and cardiac arrest, as presumed by the dispatcher. When the dispatcher let the caller take command and control, the cardiac arrest algorithm was abandoned with poor results. Dispatchers' use of the algorithm is a modifiable factor, and it should be emphasized that the algorithm must be used even if the caller is a healthcare professional. Other studies have described the phenomenon of significantly lower OHCA recognition in professionals 
than non-professional bystanders, and less use of the algorithm among healthcare professionals [12].

In our embedded theme "caller assesses the patient" we found that the dispatcher abandoned the cardiac arrest algorithm if the caller identified breathing or signs of life. Other studies have found that the description of signs of life is one of the most significant factors leading to failed recognition of OHCA [16]. Reasons for this might be that the patient does not have cardiac arrest before the arrival of the ambulance, or especially, that the patient has agonal breathing, which is present in $40 \%$ of OHCA's, and is known to delay or impede recognition of OHCA [16, 28, 33-36]. Another reason could be bystanders' difficulties in assessing breathing and consciousness, potentially leading to incorrect information passed to the dispatcher [37]. An implication of this knowledge could be to acknowledge the dispatcher, caller and other bystanders as a "first resuscitation team" working towards the common goal of recognising OHCA [38].

Inductive thematic analysis has been a strong methodological tool to meet the purpose of this study. There are limitations, which should be addressed. Most importantly, we cannot be sure if calls identified as not recognised OHCA, occurred prior to the call or after termination of the call before arrival of the ambulance. It can be argued, however, that OHCA was imminent and therefore still essential to recognise. To support the credibility of the study, investigator triangulation was used. Generalizability was increased by external studies showing similar results and by other dispatchers in Europe using the same EMD system. Reliability was achieved by saturation of data.

\section{Conclusion}

The study shows that the caller has a central role in recognising and acting upon OHCA during emergency calls. The physical and emotional proximity of the caller (bystander) as well as the caller's professional background affect the dispatcher's chances of correct recognition and handling of cardiac arrest. The dispatcher should acknowledge the triple roles of conducting patient assessment, instructing the caller, and reassuring the emotionally affected caller.

\section{Competing interests}

The authors declare that they have no competing interests.

\section{Authors' contributions}

All authors have made substantial contributions to all of the following: 1) The conception and design of the study or acquisition of data or analysis and interpretation of data, 2) Drafting the article or revising it critically for important intellectual content and 3) Final approval of the version to be submitted.

\section{Acknowledgements}

This study was supported by the European regional development fund through the Interreg IV A OKS programme [167157].

\section{Author details}

'Emergency Medical Services Copenhagen, The Capital Region of Denmark, Telegrafvej 5, 2750 Ballerup, Denmark. ${ }^{2}$ University of Copenhagen, Faculty of Health and Medical Sciences, 2200 Copenhagen N, Denmark. ${ }^{3}$ Rigshospitalet,

Trauma Centre, HOC 3193, 2100 Copenhagen Ø, Denmark.

Received: 26 April 2015 Accepted: 8 September 2015

Published online: 17 September 2015

\section{References}

1. Wissenberg M, Lippert FK, Folke F, Weeke P, Hansen CM, Christensen $E F$, et al. Association of national initiatives to improve cardiac arrest management with rates of bystander intervention and patient survival after out-of-hospital cardiac arrest. JAMA. 2013;310:1377-84.

2. Lerner EB, Rea TD, Bobrow BJ, Acker III JE, Berg RA, Brooks SC, et al. Emergency medical service dispatch cardiopulmonary resuscitation prearrival instructions to improve survival from out-of-hospital cardiac arrest: a scientific statement from the American Heart Association. Circulation. 2012;125:648-55.

3. Vaillancourt C, Stiell IG, Wells GA. Understanding and improving low bystander CPR rates: a systematic review of the literature. CJEM. 2008:10:51-65.

4. Berdowski J, Beekhuis F, Zwinderman AH, Tijssen JG, Koster RW. Importance of the first link: description and recognition of an out-of-hospital cardiac arrest in an emergency call. Circulation. 2009;1 19:2096-102.

5. Bohm K, Stalhandske B, Rosenqvist M, Ulfvarson J, Hollenberg J, Svensson L. Tuition of emergency medical dispatchers in the recognition of agonal respiration increases the use of telephone assisted CPR. Resuscitation. 2009;80:1025-8.

6. Roppolo LP, Westfall A, Pepe PE, Nobel LL, Cowan J, Kay JJ, et al. Dispatcher assessments for agonal breathing improve detection of cardiac arrest. Resuscitation. 2009:80:769-72.

7. Bang A, Herlitz J, Martinell S. Interaction between emergency medical dispatcher and caller in suspected out-of-hospital cardiac arrest calls with focus on agonal breathing. A review of 100 tape recordings of true cardiac arrest cases. Resuscitation. 2003;56:25-34.

8. Bohm K, Vaillancourt C, Charette ML, Dunford J, Castren M. In patients with out-of-hospital cardiac arrest, does the provision of dispatch cardiopulmonary resuscitation instructions as opposed to no instructions improve outcome: a systematic review of the literature. Resuscitation. 2011;82:1490-5.

9. Breckwoldt J, Schloesser S, Arntz HR. Perceptions of collapse and assessment of cardiac arrest by bystanders of out-of-hospital cardiac arrest (OOHCA). Resuscitation. 2009;80:1108-13.

10. Clark JJ, Culley L, Eisenberg M, Henwood DK. Accuracy of determining cardiac arrest by emergency medical dispatchers. Ann Emerg Med. 1994;23:1022-6.

11. Heward A, Damiani M, Hartley-Sharpe C. Does the use of the Advanced Medical Priority Dispatch System affect cardiac arrest detection? Emerg Med J EMJ. 2004;21:115-8.

12. Castrén M, Kuisma M, Serlachius J, Skrifvars M. Do health care professionals report sudden cardiac arrest better than laymen? Resuscitation. 2001:51:265-8.

13. Kuisma M, Boyd J, Väyrynen T, Repo J, Nousila-Wilk M, Holmström P. Emergency call processing and survival from out-of-hospital ventricular fibrillation. Resuscitation. 2005;67:89-93.

14. Eisenberg MS, Hallstrom AP, Carter WB, Cummins RO, Bergner L, Pierce J. Emergency CPR instruction via telephone. Am J Public Health. 1983;75:47-50.

15. Bång A, Biber B, Isaksson L, Lindqvist J, Herlitz J. Evaluation of dispatcherassisted cardiopulmonary resuscitation. Eur J Emerg Med. 1999;6:175-83.

16. Hauff SR, Rea TD, Culley LL, Kerry F, Becker L, Eisenberg MS. Factors impeding dispatcher-assisted telephone cardiopulmonary resuscitation. Ann Emerg Med. 2003:42:731-7.

17. Flynn J, Archer F, Morgans A. Sensitivity and specificity of the medical priority dispatch system in detecting cardiac arrest emergency calls in Melbourne. Prehospital Disaster Med. 2006;21:72-6.

18. Garza AG, Gratton MC, Chen JJ, Carlson B. The accuracy of predicting cardiac arrest by emergency medical services dispatchers: the calling party effect. Acad Emerg Med. 2003;10:955-60.

19. Cairns KJ, Hamilton AJ, Marshall AH, Moore MJ, Adgey AA, Kee F. The obstacles to maximising the impact of public access defibrillation: an assessment of the dispatch mechanism for out-of-hospital cardiac arrest. Heart. 2008;94:349-53. 
20. Nolan JP, Soar J, Zideman DA, Biarent D, Bossart LL, Deakin C, et al. European Resuscitation Council Guidelines for Resuscitation 2010 Section 1. Executive summary. Resuscitation. 2010;81:1219-76.

21. Danish Regions, The Laerdal Foundation for Acute Medicine. Dansk Indeks for Akuthjælp. 2013. https://www.regionh.dk/om-region-hovedstaden/ Den-Praehospitale-Virksomhed/Akutberedskabets-organisation/112-AMKVagtcentralen/Publishinglmages/Sider/AMK-Vagtcentralen/her.pdf Accessed 3 Aug 2015.

22. Malterud K. Kvalitative metoder i medisinsk forskning: en innføring. Oslo: Universitetsforlaget; 2003.

23. Gadamer HG. Sandhed og metode: grundtræk af en filosofisk hermeneutik. Copenhagen: Gyldendal; 2004.

24. Braun V, Clarke V. Successful qualitative research: a practical guide for beginners. London: Sage; 2013.

25. Culley LL, Clark JJ, Eisenberg MS, Larsen MP. Dispatcher-assisted telephone CPR: Common delays and time standards for delivery. Ann Emerg Med. 1991;20:362-6.

26. Kuisma M, Määttä T. Out-of-hospital cardiac arrests in Helsinki: Utstein style reporting. Heart. 1996;76:18-23.

27. Eisenberg MS, Carter W, Hallstrom A, Cummins R, Litwin P, Hearne T. Identification of cardiac arrest by emergency dispatchers. Am J Emerg Med. 1986;4:299-301.

28. Bång A, Ortgren PO, Herlitz J, Währborg P. Dispatcher-assisted telephone CPR: a qualitative study exploring how dispatchers perceive their experiences. Resuscitation. 2002;53:135-51.

29. Clawson JJ, Sinclair R. The emotional content and cooperation score in emergency medical dispatching. Prehospital Emerg Care. 2001;5:29-35.

30. Weslien M, Nilstun T, Lundqvist A, Fridlund B. When the unreal becomes real: family members' experiences of cardiac arrest. Nurs Crit Care. 2005;10:5-22.

31. Swor R, Khan I, Domeier R, Honeycutt L, Chu K, Compton S. CPR Training and CPR Performance: Do CPR-trained Bystanders Perform CPR? Acad Emerg Med. 2006;13:596-601.

32. Travers S, Jost D, Gillard Y, Lanoë V, Bignand M, Domanski L, et al. Out-of-hospital cardiac arrest phone detection: Those who most need chest compressions are the most difficult to recognize. Resuscitation. 2014:85:1720-5.

33. Eisenberg MS. Incidence and significance of gasping or agonal respirations in cardiac arrest patients. Curr Opin Crit Care. 2006;12:204-6.

34. Clark JJ, Larsen MP, Culley LL, Graves JR, Eisenberg MS. Incidence of agonal respirations in sudden cardiac arrest. Ann Emerg Med. 1992;21:1464-7.

35. Rea TD. Agonal respirations during cardiac arrest. Curr Opin Crit Care. 2005;11:188-91.

36. Bobrow BJ, Panczyk M, Subido C. Dispatch-assisted cardiopulmonary resuscitation: the anchor link in the chain of survival. Curr Opin Crit Care. 2012;18:228-33.

37. Møller TP, Hansen CM, Fjordholt M, Pedersen BD, Østergaard D, Lippert FK. Debriefing bystanders of out-of-hospital cardiac arrest is valuable. Resuscitation. 2014;85:1504-11.

38. Linderoth G, Hallas P, Lippert FK, Wibrandt I, Loumann S, Møller TP, et al. Challenges in out-of-hospital cardiac arrest - a study combining closed-circuit television (CCTV) and medical emergency calls. Resuscitation. 2015; doi:10.1016/j.resuscitation.2015.06.003

\section{Submit your next manuscript to BioMed Central and take full advantage of:}

- Convenient online submission

- Thorough peer review

- No space constraints or color figure charges

- Immediate publication on acceptance

- Inclusion in PubMed, CAS, Scopus and Google Scholar

- Research which is freely available for redistribution 